TRANSPARENCY AND BYPASS IN ELECTRONIC FINANCIAL MARKETS

\author{
Bruce พ. Weber \\ Department of Information systems \\ stern School of Business \\ New York University
}

Working Paper series

STERN IS-93-15 


\title{
Transparency and Bypass in Electronic Financial Markets
}

\author{
Bruce W. Weber \\ Information Systems Department \\ New York University
}

10 June 1993

\begin{abstract}
Electronic markets use information technology to disseminate information on prices, quantities, and buyer and supplier identities. In spite of the recognized benefits of electronic markets, increased visibility and transparency may introduce imperfections, and create profitable opportunities to bypass markets that generates the information. In the U.S. securities markets, dissemination of market data has equipped several firms to develop competing, off-exchange trading mechanisms that rely on market price data, but whose transactions bypass the established market. Concern is rising that the growing volume of trading occurring away from the main market may reduce liquidity, and increase transactions costs. A simulation model of securities trading in a continuous auction market (similar to the market structure of the New York Stock Exchange) is used to examine the market quality effects of increasing levels of trading activity through an offexchange dealer. Market characteristics, such as transactions costs, are measured as off-exchange trading increases from zero percent to 20 percent of the total trading volume. The results indicate that competition from an alternative trading venue reduces some trading costs borne by investors. Contrary to regulatory goals, however, off-market trading expands the role of profit-seeking dealers, and lowers the probability that some investors' orders will execute.
\end{abstract}

\section{Introduction}

Competition, innovation, and the drive to reduce costs are moving many industries toward electronic markets. Customers of airlines, mortgage-providers, and hospital suppliers are likely to perform most of their transactions electronically [HOPP90][KEME93][SHOR91]. Although screen-based commerce and electronic transactions offer benefits, closer analysis reveals shortcomings in some forms of electronic marketplaces. In some cases, electronic market systems can reduce economic benefits available to buyers and sellers. This paper examines in detail a controversy currently faced by securities regulators in the U.S. concerning 
"off-exchange" trading systems. ${ }^{1}$ The economic effects of widely-accessible, screen-based price dissemination systems are shown to have some detrimental effects on market users, and the quality of the overall market. The result is that market transparency may complicate the standard arguments for increasing applications of electronic markets. In particular, whenever markets provide not just a buyer-seller matching function, but a price-determination function as well.

Electronic markets are inter-organizational systems for bringing buyers and sellers together. The principal benefits of procurement through an electronic market are reduced search costs, and greater efficiencies compared to internal, vertically-integrated production. The reduction in search costs has been termed the "electronic-brokerage effect" by Malone et al. (1987). Compared to manually contacting potential suppliers or buyers, an electronic market enables more rapid search of a great number of potential vendors or customers, and a move closer to the economic ideal of a perfectly competitive market [BAKO91]. A second benefit is lower production costs due to economies of scale and scope available to a vendor or supplier. By serving many customers, a vendor or specialized producer will have higher volumes and lower costs. Falling transactions costs and coordination costs for external procurement should reduce firms' reliance on hierarchical relationships with vertically integrated in-house units.

While the principal benefits of electronic markets have been explored, several features of electronic markets have not been thoroughly studied. The features examined here are market transparency and the effects of market bypass. Transparency, or the visibility of activity on an electronic market, is generally considered advantageous. When prices are available to all on screen-displays, monitoring can improve and competition may intensify. Buyers or sellers can determine whether they are getting the best price. Information technology (IT) introduced at the time of the London stock market's Big Bang reforms in 1986, led traders to abandon centuriesold traditions of face-to-face trading for a screen and telephone dealing system [CLEM90]. Average trading margins (the spread between buying and selling prices) fell about 25 percent from pre-Big Bang levels, and a majority of the respondents to a survey of Exchange members found the screen-based system provided better access to market information and improved their quickness in responding to changes in trading conditions. Clemons (1992) shows how the

1 Recent studies of policy issues include "Securities Trading: SEC Action Needed to Address National Market System Issues" by the General Accounting Office (1990), "Electronic Bulls and Bears" by the Office of Technology Assessment (1990), and the Securities and Exchange Commission's Market 2000 study, due in late 1993. 
monitoring capabilities of electronic markets restrict the chances for opportunism in an outsourcing or procurement relationship. With lower ex-ante risk of worse-than-market prices or less favorable terms, firms can work together as "virtually integrated" units. Thus, electronic market transparency facilitates closer coordination between partner firms, and greater production efficiencies.

Although transparency and the ability to monitor, bring economic benefits, they also introduce the risk that the electronic market will be bypassed, or used as a tool to limit competition. The U.S. Justice Department recently forced several airlines, including American, Delta, USAir, and United, to stop providing advance details of fare changes over computer reservation systems (CRSs) [MCDO93]. It was alleged that collusive signalling was occurring among the 2 million price and schedule changes made daily over the CRSs. It was charged that airlines would post higher prices in hopes of encouraging competitors to match the fares, and to draw customers into buying tickets to avoid prices increases. The solution, imposed in the Justice Department's consent decree, prohibits airlines from giving advance notice of fare changes, or the dates of fare sales. Changes to CRS data on airline fares can now only occur once they have been advertised to the public. The changes, in effect, bring airline tickets into a spot market structure in which prices are only good at the time they are offered, with the display of future fares and advance notice of changes not allowed.

Beginning with the introduction of the telegraph by Morse in 1844, IT has been used to distribute prices from financial markets. Until recently, however, a single market tended to dominate trading in any particular issue because communication technology was too primitive to allow transactions to occur without face-to-face contact among traders. Today, the securities of major U.S. companies can be traded in multiple markets, ${ }^{2}$ and markets increasingly compete with one another to attract liquidity. ${ }^{3}$ Paradoxically, financial markets that introduce market systems to enhance their transparency, increase the threat of their market being bypassed. The greater the visibility of prices and market activity, the more attractive it is to trade outside using exchange-generated prices and quotes. Before 1978, last trade prices, but not actual quotes,

2 A widely-held security such as AT\&T's common stock is "cross-listed" and trades on the New York Stock Exchange (NYSE), regional stock exchanges in Boston, Chicago, Cincinnati, Philadelphia, San Francisco, and through over-the-counter, or "third-market" dealers, and in several overseas stock markets.

3 Several of the regional exchanges have introduced automated small order execution systems. The Chicago-based Midwestern Stock Exchange's MAX system, introduced in 1980, has the largest volume. 
were disseminated from U.S. stock exchanges. A trader or investor had to enter the market just to find out what trading prices were currently available. Traders with any interest in a security participated in the price discovery process by asking about the price, or executing a trade.

Today, exchange-generated quotes are electronically available to firms away from the market, and the technology has created close substitutes for exchange markets in a number of "third-market" dealing firms. An off-exchange dealer trades from offices using price feeds carrying market quotations from the NYSE, and other exchanges. For a principal marker center such as the New York Stock Exchange (NYSE), today's extensive information dissemination means that traders can transact at prices verifiably as good as those on the established market. Generally, the alternative trading mechanisms have less overhead expense, and will offer lower commissions and trading fees.

The growing volume of trading occurring away from the main market may reduce liquidity, and increase transactions costs. Rather than increasing competition and improving the performance, electronic market facilities may reduce market quality. In this paper we analyze the effect of off-market trading through a simulation of market trading with and without, offexchange dealing activity. As this research will demonstrate, transparency may undermine some market benefits (the "gains from trade"), or weaken the position of the market provider.

\section{Off-Exchange Trading and Regulatory Objectives}

The goals for a "National Market System (NMS)" were set out in the Amendments to the Securities Acts of 1934, which were passed in 1975 by the U.S. Congress. The Amendments' objectives were to:

(1) enhance the economic efficiency and lower the costs of transaction

(2) ensure fair competition among brokers, dealers, and markets

(3) ensure the broad availability of information on quotations and transactions

(4) provide the opportunity, consistent with efficiency and best execution, for investors' orders to be executed without the participation of a dealer 
The third objective - increasing market transparency - is believed to attract investors to a market, and improve liquidity. Yet, with perfect transparency, traders can make use of the exchange's prices without paying the costs of running the exchange. Off-exchange trading is more viable the more broadly accurate quotation information is made available. It is unclear, however, whether the ability to trade away from the central market is consistent with the NMS goals.

\section{MARKET STRUCTURE TERMINOLOGY — Glossary:}

The difference between the highest bid (to buy) quote and the lowest ask or offer (to sell) quote for a security is called the bid-ask spread. The spread is a transactions cost paid by investors. It can, however, provides a source of profits to dealer intermediaries in a market. Increased competition between markets and dealers is expected to narrow spreads.

In a continuous auction market, investors submit buy and sell orders usually through a broker. An order can be a market order, an instruction to buy or sell at the best available price in the market at that moment. Investors can also place limit orders by setting a limit price as a upper bound on the most they will pay to buy, or a lower bound on what they will sell for.

Dealers in a market post bid and offer quotes, and act as intermediaries buying and selling with investors. Dealers (or market makers) hold inventories of the securities they "make a market in", and face the risk that price changes will adversely affect the value of their position. The NASDAQ market in the U.S. is a screen-based market displaying the quotes of competing dealers.

The specialist is a regulated dealer on the floor of the NYSE. There is one specialist assigned to each stock to oversee trading and enforce the auction's rules. Only when there is an imbalance between buy and sell interest, does a specialist trade as a dealer from his or her own inventory in the stock. At any time during the trading day the best NYSE bid or offer quote may belong to the specialist, or be a limit order submitted by an investor. In practice, the specialist participates as a buyer or seller in about $20 \%$ of all NYSE trading volume.

Liquidity is the most important determinant of the attractiveness of a market, and reflects the market's ability to convert between securities and cash, rapidly and with minimal impact on the market's price. A measure of liquidity is the bid-ask spread; narrower spreads reflect lower transactions costs and greater liquidity.

Transparency in a market enables investors to know the sizes and prices of recently completed trades, and the sizes and quotes at which the next trades can be expected to execute. The research literature suggests that transparency is good for investors and enhances market competitiveness and fairness [SCHW88].

Market Structure and Information Systems in the U.S. The NYSE is largest stock market in the world, and traded shares worth $\$ 6.9$ billion daily on average in 1992. As an auction 
market, the NYSE "exposes" all orders and allows for direct investor-to-investor transactions. The NYSE market is structured as a continuous auction with a specialist assigned to each issue. There are 420 specialists with 46 specialist firms trading on the 37,000 square foot floor. Another 1,100 floor traders, brokers, and messengers make up the floor crowd. The role of the specialist is to oversee trading in their assigned securities, and to maintain a continuous bid and offer price. The specialist ensures that orders are executed according to priorities that ensure "best execution", meaning that orders to sell trade against the orders of buyers that are willing to pay the most for the shares. When investor orders are not sufficient to maintain "a fair and orderly" market, the specialist will trade as a principal from his or her own inventory.

In 1978, the Consolidated Quotation System (CQS) began to provide a screen display of the bid and offer quotes on the New York, American, and the regional stock markets, and the NASDAQ system for over-the-counter (OTC) stocks. The CQS is an electronic facility that has encouraged third-market trading by increasing the central market's transparency. In 1978, 2.4 percent of trading volume in NYSE-listed stocks occurred via "third-market" dealers. The market share of the third market grew to $3.1 \%$ in 1985 , and was $7.8 \%$ in 1992 .

The typical third market firm provides its customers, who are brokerage firms handling the orders of their retail investor customers, the ability to buy and sell at the best quotes available in any of the markets linked by the CQS. Order sizes are usually limited to 5,000 shares. Larger orders may be handled but only on request and with some negotiation on price. The third market firm trades as a dealer, buying and selling from their own inventory and generally holding a "long" (positive inventory) or "short" (negative inventory) position ${ }^{4}$ in the stock. When the volume of buy orders and sell orders received is equivalent, the third market dealer earns the spread between the bid and offer quotes posted on the CQS.

Regulatory Issues. In July 1992, The Securities and Exchange Commission (SEC) announced it was undertaking "a study of the U.S. equities markets and of the regulatory environment in which those market operate." Among the issues to be addressed in the Markets 2000 study include proprietary and third market trading systems, and market transparency. Proponents of third market dealers argue that they have successfully introduced trading innovations and their trading services provide beneficial competition to the established markets, and the specialist

4 A short position reflects the selling of securities that the trader does not own. To "cover" the short position, the trader must later purchase shares. Trading profits from a short position are realized if the price drops. 
"monopoly." At the same time, opponents of third market trading claim that it inhibits the full consolidation of trading order flow at a central market location such as the NYSE. Furthermore, foes argue that third market dealers employ "parasitic pricing" or "price piggybacking" because they rely on market transparency provided by the exchange, but they do not contribute commensurately to the price discovery process. Not surprisingly, a legal debate has arisen over the "property rights" for stock market price quotations [MUHL92]. Contending views are that they are owned by the public, or that they belong to the exchange, or that they belong to the investors or traders that provided them.

Other electronic markets for securities trading have developed in recent years. Among these are Instinet, Posit, The Crossing Network, the Arizona Stock Exchange (AZX) in the U.S., as well as Globex for futures contracts and options. Globex was launched in July, 1992, and in October 1992 was handling 2,500 futures contracts a day via 230 linked terminals in its after-hours trading sessions. The current electronic volumes are small compared to the 1.2 million contracts traded daily on the floors of the Chicago Board of Trade and the Chicago Mercantile Exchange. These screen-based markets are structured differently than those offered by third market dealers, and will not be considered in detail here.

\section{Modeling Securities Trading and Market Bypass}

Missing in the current debate on off-exchange trading systems has been a controlled study of the effects of third market activity. Because third market dealers provide the same prices as quoted in the main market, there is no systematic violation of fairness, and they appear to sharpen competition. To test for the effects of market bypass, we develop a model of the submission of trading orders to a market and the execution of trades. We evaluate market differences under identical order flow conditions, controlling only for the relative division of order flow between the main market and an off-exchange trading mechanism. Only by leaving out many important institutional details can a tractable solution be obtained [GARM76]. Instead, we incorporate institutional details affecting securities markets, and use simulation to evaluate the models.

Components of the Market Model. In the simulation model, assumptions are made about the arrival process of investors' orders, elasticity of supply and demand, and order placement strategies, price volatility, and the proportions of market and limit orders. 
Order Book. The NYSE's auction market is based on an order book containing investors' orders ranked by price (in 1/8th of a dollar units), and time of arrival. The order book also contains the specialist's bid and ask quotes $\left(B_{s}\right.$ and $\left.A_{s}\right)$. Figure 1 illustrates one possible state of the order book at some time during the trading day. The current highest bids to buy are at $\$ 32-1 / 8$ for 5 units, and the lowest offer to sell is at $\$ 33-1 / 8$ for 10 units.

FIGURE 1

\begin{tabular}{|c|c|c|c|c|c|}
\hline \multicolumn{6}{|c|}{$\begin{array}{l}\text { Specialist-Auction Market } \\
\text { Limit Order Book }\end{array}$} \\
\hline \multicolumn{2}{|c|}{ Bids } & \multirow{2}{*}{$\begin{array}{c}\text { Price } \\
\text { (in } \\
\text { eighths) }\end{array}$} & \multicolumn{3}{|c|}{ Offers } \\
\hline Orders & Qty. & & & ders & Qty. \\
\hline & & 33.3 & & 10 & 3 \\
\hline & & 33.2 & & 5 & 1 \\
\hline & & 33.1 & $A_{S}$ & 10 & 1 \\
\hline & & 33.0 & & & \\
\hline 2 & 5 & 32.7 & & & \\
\hline 2 & $\begin{array}{ll}5 & B_{S}\end{array}$ & 32.6 & & & \\
\hline 2 & 15 & 32.5 & & & \\
\hline
\end{tabular}

Large orders can have "market impact", and can move prices up for large buyers, and force them down for larger sellers. In the market situation illustrated, a seller of 10 units would receive a price of $32-\frac{3}{4}$, because the cumulative volume at the best bid is only 5 . If the market sell order was for 16 , it would also execute at $32-\frac{3}{4}$, but the specialist would participate as a buyer of 6 units. The functioning of the market for large orders is consistent with observed "block trade" discounts for large sell orders and premiums for large buy orders.

Order Arrival. Market supply and demand functions are assumed to result from the aggregated net demand schedules of investors. The functions are positively and negatively sloped respectively in price. Price-dependent Poisson processes were used to model the arrival of orders to the market. ${ }^{5}$ The order interarrival time, $T$, is exponentially distributed with $\beta_{t}$ equal to the mean interarrival time at time $t$. The mean interarrival time is set at the beginning of each experiment and assumed to hold constant. A realization at time $t$ is thus, $T_{t}=\mathscr{E}(\beta)$. The supply and demand structure follows closely those previously developed in the market

5 Using time-stamped transactions data on six stocks traded on the London Stock Exchange, a Kolmogorov-Smirnov goodness-of-fit test fails to reject the null hypothesis of exponential interarrival in 17 out of 22 sample periods at the .10 level of significance. We would expect to reject in just over 2 cases due to random realizations. While the fit is not perfect, the Poisson assumption appears sufficiently justified for capturing the typical behavior of the order arrival process. 
microstructure literature [GARM76][MEND87]. The order arrival rates are price dependent processes. Buy and sell arrival rates are step functions of the difference between the quoted price and the equilibrium value of the security.

FIGURE 2

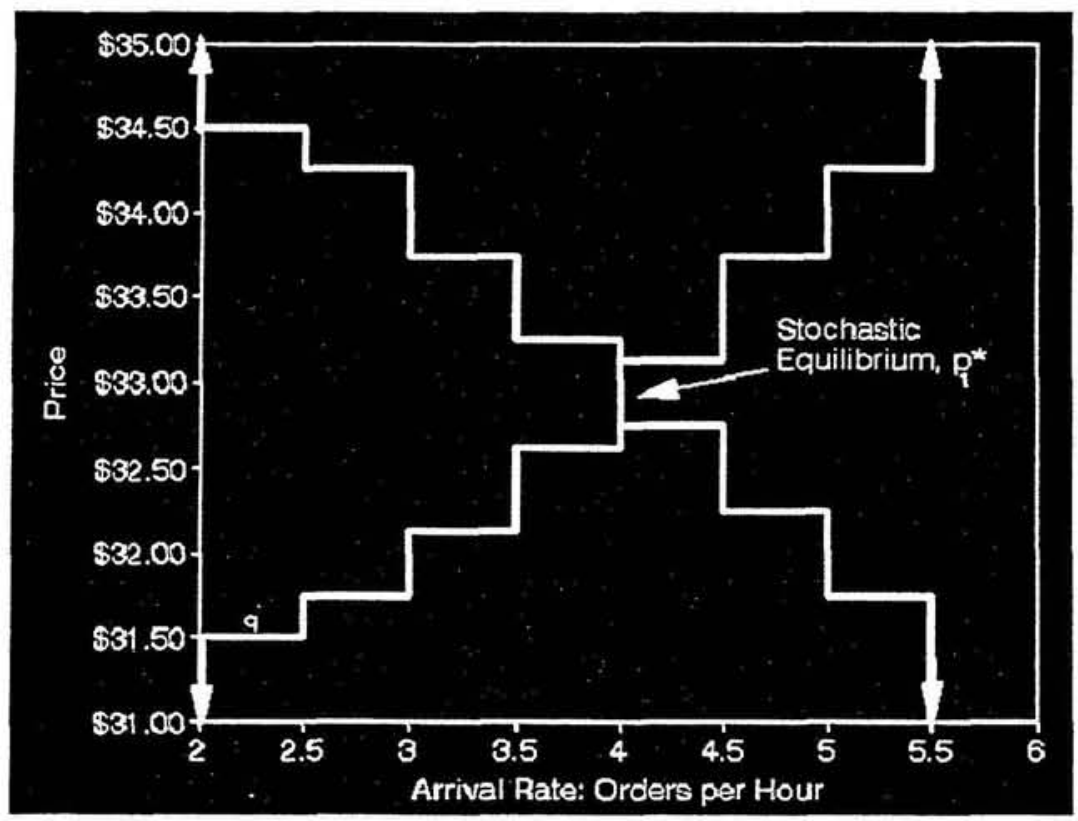

Garman termed the intersection of the supply and demand functions a "stochastic equilibrium". ${ }^{6}$

Demand/buy orders $D(p): \lambda_{B}\left(p_{i}, p^{*}\right)=a_{1}+a_{2}\left(p_{i}^{*}-p_{i}\right)$ for $p_{i}^{*}-p_{i}<\delta$

$$
\lambda_{B}\left(p_{i}, p^{*}\right)=a_{1} \text { for } p_{i}^{*}<p_{i} \quad \lambda_{B}\left(p_{i}, p^{*}\right)=a_{1}+a_{2} \delta \text { for } p_{i}^{*}-p_{i}>\delta
$$

Supply/sell orders $S(p): \quad \lambda_{s}\left(p_{j}, p^{*}\right)=a_{1}+a_{2}\left(p_{j}-p_{t}^{*}\right)$ for $p_{i}-p_{t}^{*}<\delta$

$$
\lambda_{s}\left(p_{j}, p^{*}\right)=a_{1} \quad \text { for } p_{t}^{*}>p_{i} \quad \lambda_{s}\left(p_{j}, p^{*}\right)=a_{1}+a_{2} \delta \text { for } p_{j}-p_{i}^{*}>\delta
$$

6 Representations of order generating process with finer granularity that incorporate utility maximization by individual traders' are available [MEND85][HAND91]. However we use statistical aggregates to describe group behavior, which Garman (1976) likens to a physicist that is not concerned with individual particles but with representations that describe their grouped behavior. 
The constant $a_{1}$ reflects the proportion of arrivals that are market orders. The coefficient $a_{2}$ reflects the sensitivity of buyers and sellers to discrepancies between available prices and the equilibrium value. The parameter, $\delta$, is the range around the equilibrium value from which limit prices for limit orders are generated. At a price $\mathrm{p}_{\mathrm{i}}$ lower than the equilibrium value at the time, $\mathrm{p}_{\mathrm{t}}^{*}$, the arrival rate of buy orders will exceed the rate of sell order arrivals. The resulting market buy orders and limit order bids will exceed the quantity of sell orders for belowequilibrium values. The excess demand cause prices to rise since in expectation, orders will trade against the lowest offer quotes, and add new, possibly higher priced bid quotes.

Supply, Demand, and Elasticity. The order flow is generated by simulated traders who are either potential buyers or sellers, bidding for, or offering, between one and twenty-five units of the security. Traders use either limit orders or market orders. Some limit orders will execute on arrival in the market, if there is a suitable counterpart order. For instance, a limit order to sell 3 units at $32-7 / 8$ will execute immediate if there is a bid of $32-7 / 8$ or higher available for 3 or more unit. The supply and demand functions specify arrival rates that are assumed to be symmetric, step functions in $1 / 8$ th increments around the equilibrium price. The probable prices of arriving limit orders were obtained in several interviews with NYSE specialists and floor trading staff.

TABLE 1

\begin{tabular}{|l|r|r|r|r|r|r|r|r|r||}
\hline \multicolumn{2}{|l|}{ Distribution of selecting Limit order Prices around Equilibrium Value } \\
\hline $\begin{array}{l}\text { Amount: } \\
\text { above p* (sell orders) } \\
\text { below p* (buy orders) }\end{array}$ & $1 / 8$ & $1 / 4$ & $3 / 8$ & $1 / 2$ & $5 / 8$ & $3 / 4$ & 1 & $11 / 4$ & $11 / 2$ \\
\hline Probability & 108 & 148 & 148 & 168 & 168 & 128 & 88 & $5 \%$ & 58 \\
\hline
\end{tabular}

Order Size. Buy and sell order submitted to the market vary in size from 1 to 25 units. This was a convenient normalization that reflects the empirically observable range of order sizes. The units can be scaled up to represent ten round lots, or 1,000 shares. The following approximation is used:

TABLE 2

\begin{tabular}{||l|r|r|r|r|r||}
\hline \hline Distribution & used for Trading Order Size & & \\
\hline Size & 1 & 3 & 5 & 10 & 25 \\
\hline Probability & 508 & 308 & 108 & 58 & 58 \\
\hline
\end{tabular}


Price Diffusion. The natural logarithm of the equilibrium value evolves according to a continuous random walk without return drift. To assure nonnegative prices, the log of price is used with $e_{1}$ as a normal, "white noise" term, yielding a log-normally distributed for the equilibrium price.

$$
\begin{gathered}
\ln \mathrm{p}_{\mathrm{t}}^{*}=\ln \mathrm{p}_{\mathrm{t}-\mathrm{T}}{ }^{*}+\mathrm{e}_{\mathrm{t}} \\
\text { where, } \mathrm{e}_{\mathrm{t}} \sim \mathrm{N}\left(0, \mathrm{~T} \sigma^{2}\right) \\
\Rightarrow \mathrm{p}_{\mathrm{t}}^{*} \sim \mathrm{LN}\left(\ln \mathrm{p}_{\mathrm{t}-\mathrm{T}}{ }^{*}, \mathrm{~T} \sigma^{2}\right)
\end{gathered}
$$

Notice that the price diffusion process has the Martingale property, so that the current log price is an unbiased estimator of any subsequent price:

$$
E\left(\ln p_{t+T^{*}} \mid \ln p_{t}^{*}\right)=\ln p_{t}^{*} \text { for any } T \text {. }
$$

The price diffusion process and the sensitivity of the buy and sell order arrival rates to deviations from the equilibrium means that the dealers' inventories will provide a noisy signal of the fundamental value. An increasing dealer position is denotative of quotes that are too high relative to the equilibrium value. Hence, allowing a larger position to build up is likely to lead to losses and potential bankruptcy.

Specific Assumptions. Differences in the level of third market activity leads to performance characteristics that are compared under controlled trading conditions.

Specialist Policies. The principal rule the specialist must observe is affirmative obligation which is describes in NYSE Rule 104.10(b)

In connection with the maintenance of a fair and orderly market, it is commonly desirable that a member acting as specialist engage to a reasonable degree under existing circumstances, in dealing for his or her own account when lack of price continuity, lack of depth, or disparity between supply and demand exists or is reasonably to be anticipated.

Affirmative obligation requires the specialist to make bid and offer quotes when limit orders do not provide sufficient liquidity. 
The specialist's portfolio is assumed to consist of a single stock, where $Q_{t}$ is the number of shares held by the specialist immediately after a trade at time $t$ is completed. The position at time $t$ is summarized by the pair $\left(c_{t}, v_{v}\right)$, where $c_{t}$ is cash on hand, and $v_{t}$ is the value of the shares held. Let $\mathrm{q}_{\mathrm{t}}$ be the specialist's net purchase (negative for sales, and positive for purchases) for the trade done at price $\mathrm{P}_{\mathrm{t}}$ at time $t$ :

$$
\begin{array}{ll}
\text { Share portfolio: } & \mathrm{Q}_{\mathrm{t}}=\mathrm{Q}_{\mathrm{t}-\mathrm{T}}+\mathrm{q}_{\mathrm{t}} \\
\text { Cash: } & \mathrm{c}_{\mathrm{t}}=\mathrm{c}_{\mathrm{t}-\mathrm{T}}-\mathrm{q}_{\mathrm{t}} \mathrm{P}_{\mathrm{t}} \\
\text { Value of position: } & \mathrm{v}_{\mathrm{t}}=\mathrm{Q}_{\mathrm{t}} \mathrm{P}_{\mathrm{t}}^{*}=\mathrm{Q}_{\mathrm{t}-\mathrm{T}} \mathrm{P}_{\mathrm{t}}^{*}+\mathrm{q}_{\mathrm{t}} \mathrm{p}^{*}
\end{array}
$$

The specialist does not observe the equilibrium price, but follows an inventory-driven policy to set bid and ask quotes, and also strategically adjusts his quotes in response to limit orders on the book. The policies used are consistent with the profit-maximizing specialist policies derived by Conroy and Winkler $(1981,1986)$.

A position limit of 15 units of the security was used. If the specialist is long more than 15 units or short more than 15 share, quotes are revised $1 / 8$ th downward or upward for each trade until the position is reduced. A short position is similar to a negative inventory, or a back ordered condition. The dealer must later cover the short position with purchases at the prevailing market prices. The specialist's position is private information available only to him or her. The specialist adjusts quotes down when he or she is longer than limit, and adjusts upward when shorter. Larger position limits led to specialist losses, since quote revisions lag movement in the fundamental value of the stock. Smaller position limits reduced the extent of specialist participation without contributing to profitability. After some study, the specialist's spread in the simulations was set to $\$ 0.75$ (about $2.3 \%$ of the stock's price). The specialist adjusts his or her quotes using private information on the state of the limit order book. A "thicker" limit order book on either the bid or offer side results in the specialist raising his bid or lowering his offer, thus narrowing the spread to compete with limit orders. A thinner book with fewer limit orders causes the specialist to widen his spread.

Third Marker Dealer Policies. Similar to the specialist, the dealer's portfolio consists of the stock, where $N_{t}$ is the number of shares held by the dealer immediately after a trade at time $t$ is completed and $\mathrm{n}_{\mathrm{t}}$ be the third market dealer's net purchase at time $\mathrm{t}$.

Share portfolio: $\quad N_{t}=N_{t-T}+n_{t}$ 


$$
\begin{array}{ll}
\text { Cash: } & \mathrm{c}_{\mathrm{t}}=\mathrm{c}_{\mathrm{t}-\mathrm{T}}-\mathrm{n}_{\mathrm{t}} \mathrm{P}_{\mathrm{t}} \\
\text { Value of position: } & \mathrm{v}_{\mathrm{t}}=\mathrm{N}_{\mathrm{t}} \mathrm{p}^{*}=\mathrm{N}_{\mathrm{t}-\mathrm{T} \mathrm{P}^{*}+\mathrm{n}_{\mathrm{t}} \mathrm{p}^{*}}
\end{array}
$$

Similar to the specialist, the third market dealer does not observe the equilibrium price, but instead recognizes that changes in his or her position may reflect movement in the fundamental value of the security. Also the third market dealer's position, like the specialist's, is private information available only to him or her. In contrast to the specialist, the third market dealer only accepts small orders for 5 units or less. Small orders represent 90 percent of arriving orders and 52.1 percent of the arriving volume. When the third market dealer's position exceeds his or her limit, the dealer routes an offsetting order for the amount of his or her position limit to the main market place, where they execute against available limit orders on the book, or the specialist's quotes. For example, if the third market dealer has a long position of 14 and a position limit of 15, an investor's sell order for 3 units will raise the dealer's position to 17, which is beyond the limit. As a result, a sell order for his or her position limit of 15 will be transmitted to the specialist market to execute against the best available bid quotes in the market.

Importantly, the trading rules and quote adjustment policies for the specialist and offexchange dealer lead to small positive trading profits. If their roles were not capable of generating economic rents, there would a withdrawal of dealers from the market, and a only a disintermediated market would be available to investors.

Simulation Trace. To demonstrate the comparison of the two markets under one set of trading conditions, we consider a stock with a mean interarrival time between orders of 4 minutes, and set its initial equilibrium value at 33.00. Limit orders are expected to make up two-third of total order flow, and market orders from liquidity-motivated investors accounted for the other 33.3 percent of orders. ${ }^{7}$ The equilibrium price varies according to a random walk process thereafter with standard deviation of daily returns of $3.0 \%$, or about twice the average volatility of a stock in the S\&P500 index. Limit orders that remain unexecuted after 6.5 hours

7 In 1989 , limit orders were $51 \%$ of the orders entered and $77 \%$ of the order volume entered on the DOT (Designated Order Turnaround) system, which itself accounts for $85 \%$ of all NYSE orders [RES90]. 
of trading time are canceled. Figure 3 is a trace of the simulation's execution over 20 minutes for the specialist market model. At 15:30, the order book state is displayed.

\section{FIGURE 3}

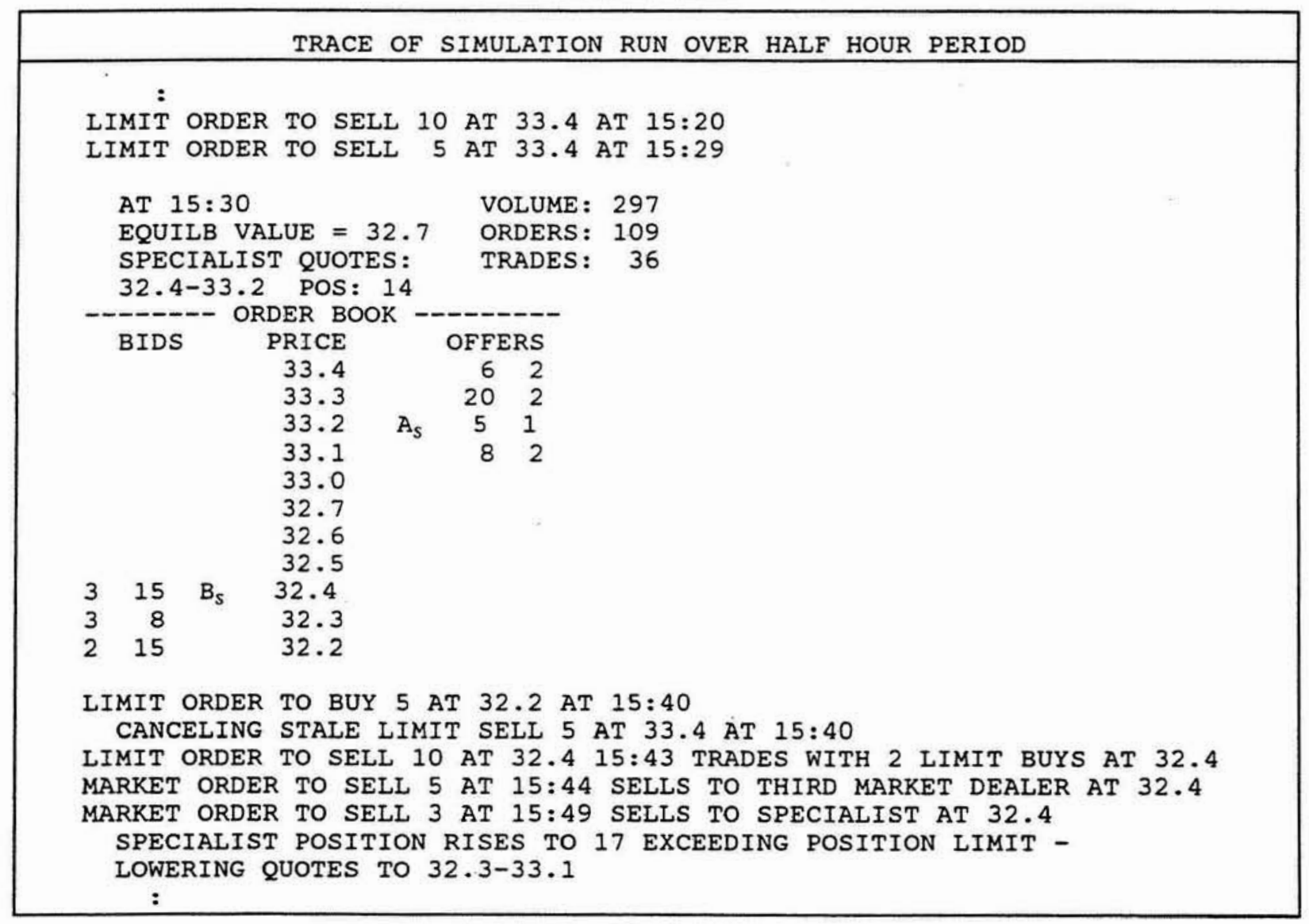

\section{Simulation Experiments and Results}

Seven different market conditions were tested, with eight replications lasting 100 trading days for each case. This provided a total data set equivalent to $7 * 8 * 100=5,600$ trading days. Several parameters were held constant across the replications. 
TABLE 3

\begin{tabular}{||lr||}
\hline Model Input Parameter & Value \\
\hline Mean Order Arrival Rate & 15 per hour \\
Mean Volume Arrival & 54.75 units per hour \\
Limit Orders (\% of Total) & $66.7 \%$ \\
Limit Orders Cancel if Unexecuted After & 6.5 hours \\
Standard Deviation of Daily Returns & $3.00 \%$ \\
Trading Day Length & 6.5 hours \\
Initial Equilibrium Price & $\$ 33.00$ \\
Specialist Position Limit & 15 \\
Third Market Dealer Position Limit & 15 \\
\hline
\end{tabular}

Each cell in Table 4 presents the averages of eight replications each covering 100 days of trading in a stock. The treatment variable is the third market dealer's share of small order flow, which is set at four different levels as indicated in the column headings. Notice that when the bypass share is $60 \%$, the third market accounts for just under $20 \%$ of the aggregate trading volume. Common random variates are used, so that each of the eight replications represents identical sample paths for the stochastic environment variables used. By using this variance reduction technique, performance differences are attributable to changes in the control variable - the share of order flow to the third market dealer - rather than the particular sample paths of the model's random deviates.

A round-trip represents the act of buying and later selling during the 100 day period. A round-trip using market orders pays a cost due to the spread between bid and offer prices, while a round-trip using limit orders realizes a gain from selling at the higher offer price and buying at the lower bid price. Limit orders however face the risk of not executing, and the risk that the price will move adversely while they are on the book. 
TABLE 4

\begin{tabular}{|c|c|c|c|c|}
\hline $\begin{array}{l}\text { Information Treatment I: Specia } \\
\text { equivalently informed order flor } \\
0.01 \text { level) }\end{array}$ & $\begin{array}{l}\text { ist and Th } \\
\text { s. } l^{*}=\mathrm{s} \\
\text { MARKET DE }\end{array}$ & Six paired t- & $\begin{array}{l}\text { test signi. } \\
\text { OF SMALL }\end{array}$ & $\begin{array}{l}\text { ive } \\
\text { ficant at } \\
\text { ORDER FLOW }\end{array}$ \\
\hline Means over 8 sample runs & 08 & 208 & 408 & $60 \%$ \\
\hline $\begin{array}{l}\text { Arriving Orders } \\
\text { Volume }\end{array}$ & & $\begin{array}{r}9,587 \\
34,933 \text { repl }\end{array}$ & $\begin{array}{l}\text { he for all } \\
\text { ications) }\end{array}$ & \\
\hline Executed Trade Volume & 23,974 & 23,954 & 23,929 & 23,958 \\
\hline Spread* (as a o of mean price) & 1.528 & 1.468 & 1.398 & 1.308 \\
\hline $\begin{array}{l}\text { Probability that a limit order } \\
\text { executes* }\end{array}$ & 55.958 & $54 \cdot 708$ & 52.818 & 50.558 \\
\hline $\begin{array}{l}\text { Expected Time until limit } \\
\text { order executes * (minutes) }\end{array}$ & 216 & 227 & 243 & 263 \\
\hline $\begin{array}{l}\text { Average Cost of a Round-Trip } \\
\text { Transaction* }\end{array}$ & $\begin{aligned} & 0.028 \phi \\
= & 0.098\end{aligned}$ & $\begin{aligned} & 0.0404 \\
= & 0.138\end{aligned}$ & $\begin{aligned} & 0.0526 \\
= & 0.178\end{aligned}$ & $\begin{aligned} & 0.0694 \\
= & 0.228\end{aligned}$ \\
\hline $\begin{array}{l}\text { Margins (Profit } \div \text { Dealer Volume) } \\
\text { Specialist* } \\
\text { Third Market Dealer* } \\
\text { Aggregate Dealership }\end{array}$ & $\begin{array}{r}0.1848 \\
\text { na } \\
0.1848\end{array}$ & $\begin{array}{l}0.1588 \\
0.0368 \\
0.1268\end{array}$ & $\begin{array}{l}0.1028 \\
0.1018 \\
0.1028\end{array}$ & $\begin{array}{l}0.0238 \\
0.1538 \\
0.0988\end{array}$ \\
\hline $\begin{array}{l}\text { Trading Volume as } 8 \text { of Total } \\
\text { Specialist* } \\
\text { Third Market Dealer* }\end{array}$ & $\begin{array}{r}16.988 \\
\mathrm{na} \\
-1 .\end{array}$ & $\begin{array}{r}15.768 \\
5.688 \\
-68\end{array}$ & $\begin{array}{l}14.818 \\
11.698\end{array}$ & $\begin{array}{l}13.208 \\
17.878\end{array}$ \\
\hline $\begin{array}{l}\text { Both Dealers' Trading Volume } \\
\text { as \& of Total* }\end{array}$ & 16.988 & 21.448 & 26.508 & 31.078 \\
\hline
\end{tabular}

Several observers have commented that the small trades routed to the third market trading systems "are likely to be those based on little or no private information. ${ }^{8}$ Since third market dealers generally operate proprietary (rather than open) trading systems, they can segment the order flow, and accept only that from brokers that are less likely to trade on price-sensitive information before the quotes used by the third market dealer have adjusted. In the model informed orders are the limit orders that are able to execute immediately due to transitory divergence between current quotes and the equilibrium value. Information is treated in a second way by routing 20 percent more of the uninformed order flow to the third market dealer, and 10 percent less of the informed order flow to the third market dealer. For instance, in the experimental setting with 40 percent of the total small order flow going to the third market dealer, in the second scenario, 60 percent of the uninformed order flow will go to the third market dealer and just 30 percent of the informed. The proportion of the total order flow routed

$8 \quad$ [KLEI92], p. 328. 
to the dealer remains the same, but what arrives is less likely to be a result of a discrepancies between the equilibrium price and the extant market quotes.

\section{TABLE 5}

\begin{tabular}{|c|c|c|c|c|}
\hline $\begin{array}{l}\text { Information Treatment II: Third } \\
\text { market share of uninformed order } \\
\text { order flows. }(*=\mathbf{s i x} \text { paired } t-t\end{array}$ & $\begin{array}{l}\text { Market Dea } \\
\text { flow, and } \\
\text { est signifi } \\
\text { MARKET DE }\end{array}$ & $\begin{array}{l}\text { aler receives } \\
10 \% \text { less of } \\
\text { icant at } 0.01 \\
\text { EALER'S SHARE }\end{array}$ & $\begin{array}{l}208 \text { more } \\
\text { the averag } \\
\text { level) } \\
\text { OF SMALL. }\end{array}$ & $\begin{array}{l}\text { than his } \\
\text { ge informed } \\
\text { ORDER FLOW }\end{array}$ \\
\hline Means over 8 sample runs & 08 & $20 \%$ & 408 & 608 \\
\hline $\begin{array}{l}\text { Arriving Orders } \\
\text { Volume }\end{array}$ & $\begin{array}{r}9,587 \\
34,933\end{array}$ & $\begin{array}{r}9,587 \\
34,933\end{array}$ & $\begin{array}{r}9,587 \\
34,933 \\
\end{array}$ & $\begin{array}{r}9,587 \\
34,933 \\
\end{array}$ \\
\hline Executed Trade Volume & 23,974 & 23,670 & 23,419 & 23,454 \\
\hline Spread* (as a 8 of mean price) & 1.528 & 1.408 & 1.308 & 1.228 \\
\hline $\begin{array}{l}\text { Probability that a limit order } \\
\text { executes }\end{array}$ & $55 \cdot 958$ & $53.37 \%$ & 50.568 & 48.498 \\
\hline $\begin{array}{l}\text { Expected Time until limit order } \\
\text { executes* (minutes) }\end{array}$ & 216 & 231 & 250 & 269 \\
\hline $\begin{array}{l}\text { Average Cost of a Round-Trip } \\
\text { Transaction* }\end{array}$ & $\begin{aligned} & 0.028 \% \\
= & 0.098\end{aligned}$ & $\begin{aligned} & 0.0494 \\
= & 0.168\end{aligned}$ & $\begin{aligned} & 0.0816 \\
= & 0.268\end{aligned}$ & $\begin{array}{r}0.094 \% \\
=0.308\end{array}$ \\
\hline $\begin{array}{l}\text { Margins (Profit } \div \text { Dealer Volume) } \\
\text { Specialist } \\
\text { Third Market Dealer* } \\
\text { Aggregate Dealership }\end{array}$ & $\begin{array}{r}0.1848 \\
\text { na } \\
0.1848\end{array}$ & $\begin{array}{l}0.1118 \\
0.2988 \\
0.1768\end{array}$ & $\begin{array}{l}0.0418 \\
0.2338 \\
0.1418\end{array}$ & $\begin{array}{l}0.0488 \\
0.2128 \\
0.1518\end{array}$ \\
\hline $\begin{array}{l}\text { Trading Volume as a of of Total } \\
\text { Specialist* } \\
\text { Third Market Dealer }\end{array}$ & $\begin{array}{r}16.98 \% \\
\text { na }\end{array}$ & $\begin{array}{r}14.828 \\
7.838\end{array}$ & $\begin{array}{l}13 \cdot 228 \\
14.378\end{array}$ & $\begin{array}{l}12 \cdot 358 \\
20.818\end{array}$ \\
\hline $\begin{array}{l}\text { Both Dealers' Trading Volume as } \\
\text { a } \% \text { of Total* }\end{array}$ & 16.988 & 22.658 & 27.598 & 33.168 \\
\hline
\end{tabular}

Space limitations preclude a full empirical validation of the output data. Based on several observable measures from the actual NYSE market, however, the models appear to provide a realistic representation. For instance, specialists on the NYSE participated as dealers in about $18.4 \%$ of trading volume in 1988 [NYSE89], compared with an average of $16.98 \%$ participation in the simulation runs without a third market dealer. Other NYSE data that verifies the simulation's output are the probability of a limit order executing is $60.0 \%$, which is similar to the $55.95 \%$ obtained as a simulation average [RES90]. The ability to segment and receive only the less informed order flow raises the third market dealer's profitability, and intensifies the impact of third market activities. For instance, the dealers' proportion of trading volume increases when the third market dealer receives segmented order flow.

Impacts of Third Market Activity. Three principal impacts of third market activity are evident in the results of the simulation analysis. 
Impact 1. Competition from a third market dealer leads to narrower quotes, and a tighter bidask spread. The greater the share of order flow that bypasses the specialist order book, the larger the reduction in the posted spread in both treatments. When the third market dealer receives $60 \%$ of the small order flow, the spread falls $14.5 \%$ and $19.7 \%$ from its base case under the two information treatments. Since the spread is a visible cost borne by investors, this effect improves the quality of the market, and should raise liquidity.

Orders that bypass the limit order book do not execute, and remove orders and price quotes in the main market. As a result limit orders that would have executed remain on the book longer, narrowing the spread in many cases. Also, greater third market volumes siphon trading away from the specialist, who is less likely to need to changes quotes in response to an excess inventory position.

Impact 2. Limit orders are disadvantaged at higher levels of third market activity. They are less likely to execute, and remain in the book longer before execution. The probability of execution falls over $5 \%$ and $7 \%$ under the two information scenarios as the third market dealer's share increases. The expected wait time before execution rises from its base case of 3 hours 36 minutes by about a hour with $60 \%$ small order share for the third market dealer. Because more of the orders that execute are market orders that pay the spread cost (buy at the offer and sell at the bid), the average round-trip transactions cost increases from its base of $0.09 \%$ of the average share price to $0.22 \%$ and $0.30 \%$ when the third market dealer receives $60 \%$ of the small order flow. A clientele effect is evident when third market activity increases. Namely, limit orders are less attractive when a substantial proportion of the order flow is routed away from the central order book and to a third market dealer. Market orders receive better treatment because narrower spreads reduce the cost of immediate executions.

Impact 3. Although third market activity reduces the specialist's trading volumes, greater bypass levels increases the overall role of dealers in the market. Without a third market dealer, the specialist's trading is about $17.0 \%$ of the total trading volume. When the third market dealer receives $60 \%$ of the small order flow in the two information treatments, the two dealers combined account for $31.1 \%$ and $33.2 \%$ of the aggregate trading volume. Third market activity and bypass of the main market leads to greater dealerization of trading. Since one of the objectives of the NMS is to provide the opportunities for investors' orders to be executed without the participation of a dealer, this is a drawback. 


\section{Interpretation and Conclusion}

Electronic markets have received considerable attention from researchers and practitioners because of their recognized benefits in reducing search costs, and improving coordination and monitoring in business relationships. The consequences of immediate and wide dissemination of information that occurs in electronic markets remains to be thoroughly examined. This research has demonstrated that market transparency can have substantial consequences by creating, in financial markets at least, profitable opportunities to bypass markets that generates the information. The dilemmas analyzed, are suggestive of a broad range of issues that will confront the organizations that implement electronic markets for products, services, or financial instruments.

In the U.S. securities markets, dissemination of market data has equipped several firms to develop competing, off-exchange trading mechanisms that rely on market price data, but whose transactions bypass the established market. As demonstrated with a simple model of order arrival and trading, there are significant differences in market performance and quality when bypass and third-market activity increases. These effects, however, are not unambiguously favorable or unfavorable. Information plays too great a role both as a signalling device and a bypass tool in many industries to make a simple conclusion the electronic markets are only for the better.

Much of the current controversy, and many of the views on off-exchange trading in the U.S. are colored by partisan interests. The exchanges and the third market dealers that bypass them are adversaries, each claiming higher ground. Not surprisingly, the specialist's profits and margins are negatively related to third market volumes; off-exchange dealing activity reduces specialist's earnings. William Donaldson, chairman of the NYSE, claims that "when someone is making an OTC (third) market in NYSE stocks, they are living off the NYSE. They make

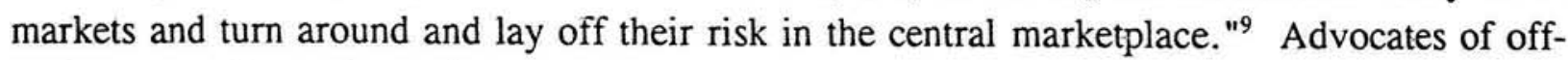
exchange trading point to increased choice and competition, and trading innovations such as automatic execution systems and 3-4 second turnaround time for order executions put in place by third market dealers.

The response may be more sophisticated electronic stock markets that integrate multiple trading mechanisms, and reduce the incentives for bypass. Steven Wunsch, developer of the

9 [HANS92], p. 100. 
Arizona Stock Exchange (AZX) argues for "trying to centralize trading through a combination of old rules and new technology." Because full information might weaken the incentive to submit orders to a transparent market, to prevent bypass, electronic market providers must determine what information dissemination strategy will maximize overall market benefits.

\section{References}

[AMIH85] Amihud, Y. and Mendelson H. "An Integrated Computerized Trading System" in Market Making and the Changing Structure of the Securities Industry, Amihud, Ho, and Schwartz (eds.), Lexington Books, 1985.

[AMIH88] Amihud, Y. and Mendelson H. "Liquidity, Volatility and Exchange Automation", Journal of Accounting, Auditing \& Finance, Fall 1988, pp. 369-395.

[BAKO91] Bakos, J.Y. "Information Links and Electronic Marketplaces: The Role of Interorganizational Information Systems in Vertical Markets", Journal of Management Information Systems, Vol. 8, No. 2, Fall 1991, pp. 31-52.

[CLEM90] Clemons, E. and Weber, B. "London's Big Bang: A Case Study of Information Technology, Competitive Impact, and Organizational Change", Journal of Management Information Systems, Vol. 6, No. 4, Spring 1990, pp. 41-60.

[CLEM92] Clemons, E. "Information Technology and the Changing Boundary of the Firm: Implications for Industrial Restructuring", Decision Sciences Working Paper \#9209-02, Wharton School, University of Pennsylvania, 1992.

[COHE85] Cohen, K., Conroy, R., and Maier, S. "Order Flow and the Quality of the Market", in Amihud, Y, Ho, T., and Schwartz, R. (eds.) Market Making and the Changing Structure of the Securities Industry, Lexington Books, 1985, pp. 93-109.

[CONR81] Conroy, R. and Winkler, R. "Informational Differences Between Limit and Market Orders for a Market Maker", Journal of Financial and Quantitative Analysis, December 1981, pp. 703-724.

[CONR86] Conroy, R and Winkler, R. "Market Structure: The Specialist as Dealer and Broker", Journal of Banking and Finance, 1986, pp. 21-36.

[FACT89] New York Stock Exchange, Fact Book, 1989. 
[GARB78] Garbade, K. "The Effect of Interdealer Brokerage on the Transactional Characteristics of Dealer Markets", Journal of Business, Vol. 51, No. 3, 1978, p. $477-498$.

[GARM76] Garman, M. "Market Microstructure", Journal of Financial Economics, Vol. 3, 1976, pp. 257-275.

[GASI79] Garbade, K. and Silber W. "Structural Organization of Secondary Markets: Clearing Frequency, Dealer Activity, and Liquidity Risk", Journal of Finance, June 1979, pp. 577-593.

[GURB91] Gurbaxani, V. and Whang, S. "The Impact of Information Systems on Organizations and Markets", Communications of the ACM, Vol. 34, No. 1, January 1991.

[HAND91] Handa, P. and Schwartz, R. "On the Desirability of Limit Order Trading", Department of Finance, New York University, November 1991.

[HANS92] Hansell, S. "Will Bill Donaldson go the Way of Gorbachev", Institutional Investor, Febraury 1992, pp. 97-102.

[HOMA85] Ho, T. and Macris R. "Dealer Market Structure and Performance", in Amihud, Y, Ho, T., and Schwartz, R. Market Making and the Changing Structure of the Securities Industry, Lexington Books, 1985, pp. 41-66.

[HOPE90] Hopper, M. "Rattling Sabre", Harvard Business Review, 1990.

[KEME93] Kemerer, C. " Mortgage Selection Systems and the Electronic Markets Hypothesis: The Case of ShelterNet", presentation at HICSS-26, Maui, Hawaii, 1993.

[KLEI92] Kleidon, A. "Market 2000: A Response" in Modernizing U.S. Securities Regulation: Economic and Legal Perspectives, Lehn, K. and Kamphuis, R. (eds.), Business One Irwin, Homewood, IL, 1992, pp. 323-332.

[MAL087] Malone, T., Yates, J, and Benjamin, R. "Electronic Markets and Electronic Hierarchies", Communications of the ACM, Vol. 30, No. 6, June 1987, pp. 484497.

[MCDO93] McDowell, E. "American Air Agrees to Limit Fare Data", New York Times, 26 February 1993, p. D2. 
[MEND85] Mendelson, H. "Random Competitive Exchange: Price Distributions and Gains from Trade", Journal of Economic Theory, Vol. 37, 1985, pp. 254-280.

[MEND87] Mendelson, H. "Consolidation, Fragmentation, and Market Performance", Journal of Financial and Quantitative Analysis, Vol. 22, June 1987, pp. 189207.

[MUHL92] Muhlherin, J.H. "Market Transparency: Pros, Cons, and Property Rights" in Modernizing U.S. Securities Regulation: Economic and Legal Perspectives, Lehn, K. and Kamphuis, R. (eds.), Business One Irwin, Homewood, IL, 1992, pp. 333-340.

[NYSE89] "NYSE: 1989 and Beyond: An Overview of an Academic Seminar", May 5, 1989, New York Stock Exchange.

[RES90] Correspondence with NYSE Research Department, October 1990.

[SCHW89] Schwartz, R. "An Electronic Call Market: Its Design and Desirability", Chapter 2 in The Challenge of Information Technology for the Securities Markets: Liquidity, Volatility, and Global Trading, Lucas, H. Jr. and Schwartz, R. (eds.) Dow Jones-Irwin, 1989.

[SHOR91] Short, J. "Transformation in Network Relationships: Evidence from Healthcare", Center for Information Systems Research, Sloan School of Management, MIT, 1991.

[WEBE91] Weber, B. Information Technology and Securities Markets: Feasibility and Desirability of Alternative Electronic Trading Systems, unpublished dissertation, University of Pennsylvania, 1991.

[WUNS92] Wunsch, S. "Background on Critical Issues Raised by Markets 2000, AZX, Inc., New York, 1992. 